\title{
Ambtshalve toepassing van EU-recht: ook financieel toezichtrecht?
}

\author{
$M r . A . G . F . A n c e r y^{*}$
}

\begin{abstract}
1 Inleiding
$\mathrm{Al}$ vele jaren is het gemeengoed onder Nederlandse rechters dat in geschillen tussen bedrijven en consumenten (hierna aangeduid als: B2C-geschillen) een plicht kan rusten op de rechter om ambtshalve toepassing te geven aan consumentenbeschermende bepalingen. De reikwijdte van die plicht wordt grotendeels bepaald door het Hof van Justitie van de Europese Unie (hierna: HvJ EU) en lijkt steeds iets verder te worden uitgebreid (par. 2). Inmiddels wordt ook vaker de vraag gesteld hoever die plicht reikt. Geldt deze bijvoorbeeld ook voor andere EU-richtlijnen ter bescherming van de zwakkere partij? ${ }^{1}$ En wordt het niet tijd dat ook strikt nationale consumentenbeschermende bepalingen op eenzelfde manier ambtshalve worden toegepast? $?^{2}$
\end{abstract}

Een categorie bepalingen die (mede) bedoeld is om consumenten te beschermen en waarvan de regelgeving in sterke mate wordt beïnvloed door Europese richtlijnen en verordeningen, ${ }^{3}$ maar ten aanzien waarvan mij nog geen uitspraken bekend zijn waarin hieraan ambtshalve (en buiten de grenzen van de rechtsstrijd) toepassing wordt gegeven, betreft het financieel

* Mr. A.G.F. Ancery is verbonden aan het Wetenschappelijk Bureau van de Hoge Raad der Nederlanden.

De auteur schrijft deze bijdrage op persoonlijke titel.

1. Vgl. onder meer J.W. Rutgers, Ambtshalve toepassing van Europees recht in het civiele geding, in: R.J.C. Flach e.a. (red.), Amice. Liber amicorum Rutgers, Deventer: Kluwer 2005, p. 295-303; M. Freudenthal \& R.H. van Ooik, Optimale handhaving van het Europese recht in het Nederlandse privaatrecht, in: A.S. Hartkamp, C.H. Sieburgh \& L.A.D. Keus (red.), De invloed van het Europese recht op het Nederlandse privaatrecht, Deventer: Kluwer 2007, p. 45-77; H.J. Snijders, Ambtshalve aanvulling van gronden van Europees recht in burgerlijke zaken herijkt, WPNR 2008/6761, p. 541-552; A.G.F. Ancery \& H.B. Krans, Ambtshalve toepassing van Europees consumentenrecht, RMThemis 2009, p. 191-200; A.S. Hartkamp, De verplichting tot ambtshalve toepassing van Europees recht door de Nederlandse rechter, Trema 2010, p. 136-143.

2. A.G.F. Ancery \& H.B. Krans, Ambtshalve toepassing van consumentenrecht: grensbepaling en praktische kwesties, AA 2016, p. 827 e.v.

3. Bijv., en niet uitputtend: Richtlijn 2004/39/EG van 21 april 2004 betreffende markten voor financiële instrumenten (MiFID I), thans vervangen door Richtlijn 2014/65/EU van 15 mei 2014 betreffende markten voor financiële instrumenten (MiFID II); Verordening (EU) 600/2014 van 15 mei 2014 betreffende markten voor financiële instrumenten (MiFIR); Verordening (EU) 596/2014 van 16 april 2014 betreffende marktmisbruik (MAR); Verordening 2017/1129 van 14 juni 2017 betreffende het prospectus dat gepubliceerd moet worden wanneer effecten aan het publiek worden aangeboden of tot de handel worden toegelaten, waarmee de eerder geldende Prospectusrichtlijn is ingetrokken (Prospectusverordening). toezichtrecht. Dan kan worden gedacht aan bepalingen die voortvloeien uit de EU-rechtelijke MiFID (I/II)-richtlijn, maar bijvoorbeeld ook aan regels omtrent marktmisbruik (zoals neergelegd in de Verordening marktmisbruik (ook wel aangeduid als MAR)). Busch heeft voor dit aspect meerdere malen aandacht gevraagd, ${ }^{4}$ reden genoeg om deze eens aan een nadere beschouwing te onderwerpen.

Wat hierbij een rol speelt, is de aard van de regels, die vooral gericht zijn op toezicht en niet zozeer op het ingrijpen in privaatrechtelijke verhoudingen (par. 3). Zij kunnen echter wel daarop ingrijpen (par. 4) en verschillen dan wellicht niet zoveel meer met bepalingen die dienen ter omzetting van EUrechtelijke consumentenbeschermende richtlijnen (par. 5).

\section{Ambtshalve toepassing van EU-recht: de stand van zaken}

In het algemeen voltrekt de rechtspraak van het $\mathrm{HvJ}$ EU voor wat betreft de vraag naar de verplichting tot ambtshalve toepassing zich langs twee lijnen. Enerzijds speelt die discussie in het mededingingsrecht met betrekking tot het kartelverbod. Die bepaling is door het HvJ EU aangemerkt als een bepaling van openbare orde en dient ambtshalve door de rechter te worden toegepast, desnoods buiten de grenzen van de rechtsstrijd. ${ }^{5}$ Dat laatste zal overigens in de praktijk vrij moeilijk zijn, omdat de rechter meestal niet zal beschikken over de daarvoor benodigde feitelijke informatie en deze ook niet eenvoudig boven tafel zal weten te krijgen. ${ }^{6}$ Anderzijds speelt dezelfde discussie in het consumentenrecht. Daar is de kwestie iets ingewikkelder.

De meeste rechtspraak over de plicht tot ambtshalve toepassing van consumentenrecht doet zich voor in de context van de toetsing van mogelijkerwijs oneerlijke bedingen. Waar het

4. D. Busch \& C. van Dam, A Bank's Duty of Care: Perspectives from European and Comparative Law, in: D. Busch \& C. van Dam (red.), A Bank's Duty of Care: Oxford and Portland, Oregon: Hart Publishing 2017, p. 422 en 433-435; D. Busch, De invloed van het Europees financieel toezichtrecht op het Nederlands privaatrecht, WPNR 2017/7175, p. 1019; D. Busch, Het civiel effect van de Marktmisbruikverordening, FR 2016, afl. 12, p. 535; D. Busch \& T.M.C. Arons, Van woekerpolissen, rechtszekerheid en privaatrechtelijke gevolgen door een Luxemburgse bril, AA 2015, p. 701.

5. Hierover: A.G.F. Ancery, Ambtshalve toepassing van EU-recht (diss. Groningen), Deventer: Kluwer 2012, p. 165 e.v.

6. Ancery 2012, p. 173-175 (punt 278). In deze lijn: concl. A-G Van Peursem van 26 juni 2015, ECLI:NL:PHR:2015:993, onder 2.1 . 
HvJ EU in de Océano-zaak nog voorzichtig overwoog dat de rechter bevoegd was om ambtshalve te beoordelen of een forumkeuzebeding als oneerlijk beding was aan te merken, werd deze bevoegdheid in de Cofidis-zaak uitgebreid tot alle bedingen, ${ }^{8}$ en werd de bevoegdheid in de Mostaza Claro-zaak een verplichting 9 die volgens de Pannon-zaak ook buiten de grenzen van de rechtsstrijd dient te worden uitgeoefend ${ }^{10}$ en ten aanzien waarvan de rechter zelfs een plicht heeft tot actieve feitengaring, aldus de Pénzügyi-zaak ${ }^{11}$ in combinatie met het arrest van de Hoge Raad in de zaak Heesakkers/Voets. ${ }^{12}$

Kortom, de rechter is in geval van achterliggende consumentenbeschermende EU-richtlijnen verplicht om ambtshalve toepassing te geven aan consumentenbeschermende bepalingen buiten de grenzen van de rechtsstrijd. ${ }^{13}$

De vraag is: waarom? Daarvoor geeft het $\mathrm{HvJ}$ EU de volgende ratio. Consumenten verkeren ten opzichte van de professionele partij waarmee zij zaken doen in een zwakkere positie, zowel economisch als sociaal-maatschappelijk. Zo hebben consumenten vaak geen weet van hun juridische positie en te weinig financiële middelen om zich te laten bijstaan door een advocaat, dan wel om überhaupt in rechte te verschijnen. Om te voorkomen dat ze gespeend blijven van de hun toekomende bescherming, dient de rechter zich actief in te zetten om toepassing te geven aan de consumentenbeschermende bepalingen. Waar het eigenlijk om gaat, is dat op die manier het doel van de richtlijn bereikt kan worden. Zonder ambtshalve ingrijpen is het onmogelijk om het doel van de richtlijn - oneerlijke bedingen binden de consument niet - te bereiken. ${ }^{14}$

Dit is niet beperkt gebleven tot de Richtlijn oneerlijke bedingen. Ook voor wat betreft de Richtlijn consumentenkrediet, ${ }^{15}$ de Richtlijn buiten verkoopruimten gesloten overeenkomsten $^{16}$ en de Richtlijn consumentenkoop ${ }^{17}$ heeft het HvJ EU

7. HvJ EG 27 juni 2000, C-244/98, ECLI:EU:C:2000:346, NJ 2000/730 (Océano).

8. HvJ EG 21 november 2002, C-473/00, ECLI:EU:C:2002:705, NJ 2003/703 m.nt. M.R. Mok (Cofidis).

9. HvJ EG 26 oktober 2006, C-168/05, ECLI:EU:C:2006:675, NJ 2007/201 m.nt. M.R. Mok (Mostaza Claro).

10. HvJ EG 4 juni 2009, C-243/08, ECLI:EU:C:2009:350, NJ 2009/395 m.nt. M.R. Mok (Pannon).

11. HvJ EU 9 november 2010, C-137/08, ECLI:EU:C:2010:659, NJ 2011/41 m.nt. M.R. Mok (Pénzügyi).

12. HR 13 september 2013, ECLI:NL:HR:2013:691, NJ 2014/274 m.nt. H.B. Krans (Heesakkers/Voets), waarover onder meer: A.G.F. Ancery, Ambtshalve toepassing van consumentenbeschermend EU-recht, MvV 2013, afl. 12, p. 329-339.

13. A.G.F. Ancery \& H.B. Krans, Ambtshalve toepassing van consumentenrecht: grensbepaling en praktische kwesties, AA 2016, p. 825-830.

14. Vgl. de hiervoor in noot $7 \mathrm{t} / \mathrm{m} 11$ aangehaalde zaken, die alle op de Richtlijn oneerlijke bedingen betrekking hadden.

15. HvJ EG 4 oktober 2007, C-429/05, ECLI:EU:C:2007:575, NJ 2008/37 m.nt. M.R. Mok (Rampion) en HvJ EU 16 november 2010, C-76/10 (Pohotovost).

16. HvJ EU 17 december 2009, C-227/08, ECLI:EU:C:2009:792, NJ 2010/225 m.nt. M.R. Mok (Martín Martín).

17. HvJ EU 13 oktober 2013, C-32/12, ECLI:EU:C:2013:637, TvC 2014/3 m.nt. A.G.F. Ancery (Hueros) en HvJ EU 4 juni 2015, C-497/13, ECLI:EU:C:2015:357, NJ 2016/148 (Faber). in soortgelijke zin geoordeeld. Verscheidene auteurs hebben betoogd dat de verplichting zoals deze voortvloeit uit de rechtspraak van het HvJ EU met betrekking tot de Richtlijn oneerlijke bedingen kan worden doorgetrokken naar andere consumentenbeschermende richtlijnen. ${ }^{18}$ Ik deel dat standpunt. ${ }^{19}$

\section{Aard van het toezichtrecht}

Om te bepalen wat het primaire doel is van het toezichtrecht dient onderscheid te worden gemaakt in het type toezicht waarvan sprake is. Toezicht heeft in het algemeen een drietal doelen:

1. het bevorderen van de stabiliteit van het systeem;

2. het bevorderen van de soliditeit van financiële instellingen; en

3. het bevorderen van goed gedrag en transparantie op de financiële markten. ${ }^{20}$

In de Wet op het financieel toezicht (Wft) zijn die doelen in art. 1:24 en 1:25 Wft en de daarop geboden toelichting gespecificeerd in toezicht op solvabiliteit en liquiditeit, toezicht op de ordentelijkheid en transparantie van financiële marktprocessen, het bewaken van zuivere verhoudingen tussen marktpartijen en het borgen van een zorgvuldige behandeling van cliënten. $^{21}$

Deze laatste twee doelstellingen - het zorg dragen voor zuivere verhoudingen tussen marktpartijen en het borgen van een zorgvuldige behandeling van cliënten - vertonen sterke gelijkenis met de doelen van consumentenbeschermende richtlijnen en de ratio die het HvJ EU aan zijn rechtspraak over de ambtshalve toetsing aan consumentenbeschermende bepalingen ten grondslag legt. Welke regels kunnen in het algemeen als bijdragend aan die doelstellingen worden aangemerkt?

In dat verband dient in herinnering te worden geroepen dat er een tweedeling valt te maken in het toezicht: enerzijds zijn er regels die zien op prudentieel toezicht, anderzijds zijn er regels die zien op gedragstoezicht. ${ }^{22}$ Waar het prudentieel toezicht volgens art. 1:24 Wft ziet op het bewaken van de solvabiliteit en liquiditeit van financiële ondernemingen en de stabiliteit van het financiële stelsel, ziet het gedragstoezicht volgens art. 1:25 Wft op ordentelijke financiëlemarktprocessen, zuivere verhoudingen tussen marktpartijen en een zorgvuldige behandeling van cliënten. Ook gedragstoezicht dient, blijkens art. 1:25 lid $1 \mathrm{Wft}$, 'mede (...) het belang van de stabiliteit van het financiële stelsel (...)'. Een scherpe afbakening is dan ook las-

18. Vgl. onder meer A.S. Hartkamp, Ambtshalve toepassing van Europees consumentenrecht, AA 2015, afl. 3, p. 222 e.v. en H.B. Krans in zijn annotatie onder Heesakkers/Voets, NJ 2014/274, in fine.

19. Dat moge reeds blijken uit het hiervoor aangehaalde Ancery 2013 en A.G.F. Ancery \& C.M.D.S. Pavillon, De rechterlijke lijdelijkheid in rook opgegaan? De ambtshalve toepassing van de consumentenkoopregels nader toegelicht, $\mathrm{MvV} 2015$, afl. 9, p. 243-254.

20. L.J. Silverentand \& F.W.J. van der Eerden (red.), Hoofdlijnen Wft, Deventer: Wolters Kluwer 2015, p. 2.

21. Silverentand \& Van der Eerden 2015, p. 6.

22. Vgl. E.J. van Praag, Europees financieel toezicht, Den Haag: Boom juridisch 2017, p. 55-56 
tig. Gedragstoezicht ziet in het algemeen op het externe handelen van ondernemingen, waarbij beoordeeld wordt of partijen op de financiële markten correct worden behandeld en goed worden geïnformeerd. ${ }^{23}$

De memorie van toelichting op art. 1:25 Wft vermeldt in dit verband het volgende:

'In het bijeenbrengen van vraag en aanbod op de kapitaalmarkt is een efficiënte markt een vereiste. Marktimperfecties kunnen grote financiële gevolgen hebben voor deelnemers aan de financiële markten en hebben hun uitstraling naar de gehele economie. Dit betekent ten eerste dat de voorwaarden gecreëerd moeten worden voor marktplaatsen waar vraag en aanbod bijeen kunnen komen (ordelijkheid). Voor een efficiënte financiële markt is het vervolgens van belang dat iedere deelnemer toegang heeft tot de relevante informatie om beslissingen te nemen (transparantie) en dat er regels zijn op basis waarvan deelnemers transacties met elkaar kunnen aangaan en die bijdragen aan het bereiken van marktevenwicht (zuivere verhoudingen). De zorgvuldige omgang met cliënten staat voor een deel in het teken van deze doelstelling. Het vertrouwen in de financiële markten als geheel kan worden geschaad als cliënten onzorgvuldig worden behandeld. Daarnaast is er ook een eigen betekenis te hechten aan een zorgvuldige omgang met cliënten, namelijk consumentenbescherming op een terrein met aanzienlijke informatie-asymmetrie tussen aanbieders en cliënten waar voor de individuele cliënt aanzienlijke financiële belangen spelen. Dit laat overigens onverlet dat alle partijen op de financiële markten, waaronder cliënten, ook een eigen verantwoordelijkheid hebben. 24

Het gedragstoezicht is primair gericht op de bescherming van de cliënt en het opheffen van onevenwichtigheden op de financiële markten. In de hiervoor aangehaalde rechtspraak van het $\mathrm{HvJ}$ EU vormen de bescherming van de consument en het opheffen van de sociaaleconomische dan wel juridische ongelijkheid de reden om een plicht tot ambtshalve toepassing van consumentenbeschermende regels te aanvaarden. Als de plicht tot ambtshalve toepassing zich ook zou uitstrekken tot regels van financieel toezichtrecht, ligt het in ieder geval voor de hand dat regels van gedragstoezicht hieronder zullen worden geschaard.

Met het voorgaande is overigens niet gezegd dat regels die zien op prudentieel toezicht niet zouden strekken tot bescherming van de cliënt. Zij zijn echter primair gericht op de solvabiliteit en liquiditeit van financiële ondernemingen en behelzen doorgaans bedrijfseconomische verplichtingen. Hoewel het uiteindelijke achterliggende doel wel is het beschermen van de afne-

23. Van den Hurk, in: GS Toezicht financiële markten, art. 1:25, aant. 5.3, onder verwijzing naar P.M. Koster, Ontwikkeling van het gedragstoezicht op de financiële markten, TvOB 2005, afl. 1, p. 17.

24. Kamerstukken II 2003/04, 29708, 3, p. 28-29. mers, ${ }^{25}$ lenen normen van prudentieel toezicht zich niet goed voor directe toepassing in privaatrechtelijke verhoudingen.

Ook normen van gedragstoezicht zijn echter niet in de eerste plaats bestemd om in privaatrechtelijke verhoudingen te worden geëffectueerd. Via interventie door een toezichthouder (doorgaans de AFM of DNB) wordt bewerkstelligd dat de financiële onderneming de op haar van toepassing zijnde regels van gedragstoezicht naleeft, waardoor de cliënt in het algemeen wordt beschermd en niet zonder meer in concrete voorliggende gevallen. ${ }^{26}$ In die zin vertoont het doel van het gedragstoezicht meer directe overeenkomsten met de aan de rechtspraak van het $\mathrm{HvJ} \mathrm{EU}$ over ambtshalve toepassing van consumentenbeschermende regels ten grondslag liggende ratio, maar zit er ook een fundamenteel verschil tussen die consumentenbeschermende regels en regels van gedragstoezicht, namelijk de mate waarin de regels bedoeld zijn om privaatrechtelijke verhoudingen te beheersen. Precies dat punt speelde in de arresten van het $\mathrm{HvJ}$ EU in de zaken Genil ${ }^{27}$ en Nationale Nederlanden/Van Leeuwen. ${ }^{28}$

Kan een nationale rechter in civilibus strikter of soepeler zijn voor een financiële onderneming dan de op deze onderneming van toepassing zijnde publiekrechtelijke toezichtbepalingen? Over die vraag is uitvoerig gedebatteerd in de literatuur. ${ }^{29}$

Het HvJ EU diende in de zaak Genil te oordelen over twee cliënten die een renteswapovereenkomst hadden gesloten en ten aanzien van wie de geschiktheids- of passendheidstoets (afhankelijk van de kwalificatie van de dienstverlening) niet was uitgevoerd. De verwijzende Spaanse rechter wilde onder meer van het $\mathrm{HvJ}$ EU weten welke contractuele gevolgen aan het uitblijven van deze toets dienden te worden verbonden. Het HvJ EU beantwoordde die vraag als volgt:

25. Vgl. Kamerstukken II 2003/04, 29708, 3, p. 29.

26. Idem.

27. HvJ EU 30 mei 2013, C-604/11, ECLI:EU:C:2013:344 (Genil/Bankinter).

28. HvJ EU 29 april 2015, C-51/13, ECLI:EU:C:2015:286, NJ 2016/352 m.nt. M.M. Mendel (Nationale Nederlanden/Van Leeuwen).

29. Busch en Arons bepleiten dat de maximumharmonisatie van de MiFID (I/II)-richtlijn tot gevolg heeft dat de civiele rechter niet minder of verdergaande normen mag toepassen dan die volgen uit de Richtlijn; zie Busch \& Arons 2015, p. 696 e.v. Zie ook D. Busch, De civiele zorgplicht van banken tegenover professionele beleggers - renteswaps met (semi-)publieke instellingen en het MKB, Ondernemingsrecht 2013/33 en D. Busch, Het 'civiel effect' van MiFID: Europese invloed op aansprakelijkheid van vermogensbeheerders, Ondernemingsrecht 2012/12. Wallinga en Cherednychenko betogen dat de richtlijn geen privaatrechtelijke uitstraling heeft en de civiele rechter daarmee strenger of soepeler mag zijn dan het toezichtrecht voorschrijft; zie M.W. Wallinga \& O.O. Cherednychenko, Nationale Nederlanden/Van Leeuwen: was de uitspraak het wachten waard?, NTBR 2016, afl. 3, p. 15-21; M.W. Wallinga, Financiële dienstverlening, publiekrechtelijke gedragsregels en privaatrechtelijke normstelling: lessen uit Duitsland en Europa, NTBR 2014, afl. 8, p. 288-298. Hage lijkt zich hier enigszins tussenin te positioneren en betreurt het gebrek aan maximumharmonisatie, zonder overigens te betogen dat een verdergaande privaatrechtelijke benadering onmogelijk zou zijn; zie C.A. Hage, Informatieplichten maken een wijs man?!, NTHR 2017, afl. 5, p. 265-271 (hierna: Hage 2017a). 
'In dit verband moet erop worden gewezen dat artikel 51 van richtlijn 2004/39 weliswaar bepaalt dat administratieve maatregelen of administratieve sancties worden opgelegd aan de verantwoordelijke personen indien de ter uitvoering van deze richtlijn vastgestelde bepalingen niet worden nageleefd, maar dat deze bepaling noch preciseert dat de lidstaten contractuele gevolgen moeten vaststellen voor gevallen waarin overeenkomsten worden gesloten waarbij de verplichtingen van de bepalingen van nationaal recht ter omzetting van artikel 19 , leden 4 en 5 , van richtlijn 2004/39 niet worden nagekomen, noch duidelijk aangeeft welke gevolgen daaraan kunnen worden verbonden. Bij ontstentenis van een Unieregeling is het een aangelegenheid van het interne recht van elke lidstaat om de contractuele gevolgen van de niet-nakoming van deze verplichtingen vast te stellen, met inachtneming van het gelijkwaardigheids- en het doeltreffendheidsbeginsel (zie in die zin arrest van 19 juli 2012, Littlewoods Retail e.a., C-591/10, nog niet gepubliceerd in de Jurisprudentie, punt 27 en aldaar aangehaalde rechtspraak). ${ }^{30}$

Kortom, de vraag wat de privaatrechtelijke gevolgen zijn van het niet-naleven van normen die voortkomen uit de MiFID Irichtlijn wordt niet bestreken door de richtlijn. Uit de verwijzing naar de administratieve maatregelen en administratieve sancties volgt mijns inziens dat het HvJ EU de aan de MiFID I-richtlijn te ontlenen normen ziet als publiekrechtelijke toezichtwetgeving. Daarmee is geenszins gezegd dat er in privaatrechtelijke verhoudingen geen waarde mag worden toegekend aan die regelgeving, mits het zich maar verdraagt met het gelijkwaardigheids- en effectiviteitsbeginsel.

In de zaak Nationale Nederlanden/Van Leeuwen betrof het de Richtlijn levensverzekeringen. De zaak gaat over het volgende. Van Leeuwen sluit bij Nationale Nederlanden een levensverzekering af met een beleggingsonderdeel, waarvan de waardeopbouw op de einddatum afhangt van de ontwikkeling van de beleggingen. Gedurende de looptijd wordt een vast gegarandeerd kapitaal verzekerd, dat wordt uitgekeerd als de verzekeringnemer voor de einddatum komt te overlijden. Op grond van de verzekeringsovereenkomst dient Van Leeuwen bij aanvang en periodiek een brutopremie te voldoen, die wordt belegd in de door de verzekeringnemer gekozen beleggingsfondsen. Op deze brutopremies worden periodiek kosten in rekening gebracht, evenals risicopremies voor de ingebouwde overlijdensrisicodekking. Voorafgaand aan het aangaan van de overeenkomst is Van Leeuwen een voorstel verstrekt, waarin een drietal voorbeeldkapitalen wordt genoemd op basis van verschillende rendementen en beheerskosten. In dat voorstel is tevens genoemd dat het verschil tussen het product- en fondsrendement afhankelijk is van de verzekerde risico's, de verschuldigde kosten en eventueel aanvullende dekkingen. $\mathrm{Na}$ het aangaan van de overeenkomst ontstaat een geschil tussen Nationale Nederlanden en Van Leeuwen over de bedragen die door Nationale Nederlanden in mindering worden gebracht op de brutopremies. Meer in het bijzonder speelt of Nationale Nederlanden voorafgaand aan het aangaan van de verzekering aan Van Leeuwen voldoende informatie heeft verschaft over deze kosten.

De Rechtbank Rotterdam stelt vast dat Nationale Nederlanden heeft voldaan aan de op haar rustende verplichtingen uit hoofde van de toepasselijke richtlijn, maar dat zij niettemin heeft gehandeld in strijd met de open/ongeschreven regels van Nederlands recht, zoals de zorgplicht van de verzekeraar, de precontractuele goede trouw en de redelijkheid en billijkheid. De rechtbank stelt het HvJ EU de vraag of het mogelijk is dat het Nederlandse recht met zich brengt dat de verzekeraar meer gegevens dient te verstrekken dan waartoe deze op grond van de richtlijn gehouden is, alsmede of daarbij nog een rol speelt wat naar Nederlands recht het gevolg zou zijn van het nietverstrekken van die gegevens.

Het HvJ EU antwoordt als volgt:

'Op de eerste vraag moet bijgevolg worden geantwoord dat artikel 31 lid 3 Derde levensrichtlijn aldus moet worden uitgelegd dat het niet eraan in de weg staat dat een verzekeringnemer op grond van algemene beginselen van intern recht, zoals de in het hoofdgeding aan de orde zijnde "open en/of ongeschreven regels", gehouden is de verzekeraar bepaalde informatie te verstrekken in aanvulling op die vermeld in bijlage II bij die richtlijn, mits - het is aan de verwijzende rechterlijke instantie om dit te verifiëren de verlangde informatie duidelijk en nauwkeurig is en noodzakelijk voor een goed begrip door de verzekeringnemer van de wezenlijke bestanddelen van de verbintenis en zij voldoende rechtszekerheid waarborgt. ${ }^{31}$

De te verlangen extra informatie moet derhalve aansluiten bij het doel van de richtlijn, zijnde het bevorderen dat de consument duidelijke en nauwkeurige informatie ontvangt over de wezenlijke kenmerken van het product. Bij deze beoordeling makt het, zo overweegt het $\mathrm{HvJ} \mathrm{EU}$, in het geheel niet uit welke gevolgen door het Nederlandse recht worden verbonden aan het niet-naleven van deze verplichting.

Het is dus, zo volgt ook uit Nationale Nederlanden/Van Leeuwen, niet onmogelijk om verdergaande privaatrechtelijke verplichtingen te introduceren dan die welke voortvloeien uit publiekrechtelijke toezichtwetgeving, maar er zijn kaders waarbuiten niet getreden mag worden. Zo dienen de aanvullende verplichtingen functioneel van aard te zijn en elementaire rechtsbeginselen, waaronder in ieder geval het rechtszekerheidsbeginsel, te respecteren. Met andere woorden, de financiële onderneming dient niet te worden geconfronteerd met

31. Punt 34 . 
belastende, overbodige verplichtingen en verplichtingen waarvan zij de reikwijdte onmogelijk zou kunnen overzien. ${ }^{32}$

Zo er al een algemene lijn uit beide uitspraken van het HvJ EU kan worden gedestilleerd, is dat deze. Verdergaande privaatrechtelijke verplichtingen dan die welke voortvloeien uit publiekrechtelijke toezichtwetgeving zijn niet principieel onmogelijk, zelfs niet in geval van een maximumharmoniserende richtlijn, zoals de MiFID-richtlijn. In die zin staan publiekrechtelijke toezichtwetgeving en privaatrechtelijke open normen wat verder van elkaar af. Maar tegelijk volgt uit het arrest in de zaak Nationale Nederlanden/Van Leeuwen dat het privaatrecht niet onbeperkt aanvullende verplichtingen kan creëren voor een financiële onderneming. Bij het formuleren van aanvullende verplichtingen lijken functionaliteit, rechtszekerheid, gelijkwaardigheid en effectiviteit in ieder geval randvoorwaarden. Publiek- en privaatrecht gaan aldus bezien hand in hand.

\section{Gedragstoezicht en privaatrechtelijke verhoudingen}

In toenemende mate worden privaatrechtelijke normen in publiekrechtelijke toezichtwetgeving neergelegd. De handhaving van de normen verplaatst zich dan van de civiele rechter naar de toezichthouder. ${ }^{33}$ Handhaving is in dat geval veel meer gericht op preventie van bepaald onwenselijk gedrag en geschiedt in het algemeen belang, ${ }^{34}$ in tegenstelling tot privaatrechtelijke handhaving, die vooral ex post plaatsvindt ter bescherming van concrete, individuele belangen. ${ }^{35}$

Toezichtwetgeving die ziet op financiële markten is, zo werd hiervoor al besproken, ultimo gericht op bescherming van zwakkere partijen (doorgaans de cliënt van de financiële onderneming). Die bescherming zou via het privaatrecht onvoldoende kunnen worden verzekerd en om die reden is handhaving opgedragen aan toezichthouders. ${ }^{36}$ Het publieke toezichtrecht is nodig om de voorwaarden voor goed werkende financiële markten te creëren, waarop partijen op voet van gelijkheid met elkaar transacties kunnen aangaan. Waar dat in concrete gevallen tot schade bij een van de partijen leidt, is het privaatrecht het aangewezen handhavingsmechanisme. ${ }^{37}$ In die zin zijn publiek- en privaatrecht in dezen complementair aan elkaar. Veel publiekrechtelijke regels hebben ook een privaatrechtelijke oorsprong en zijn in een publiekrechtelijke pendant omgezet, zodat ze door de toezichthouder kunnen worden gehandhaafd.

32. Vgl. de noot van M.M. Mendel onder het arrest, NJ 2016/352, onder 4 e.v. en Hage 2017a, p. 269 e.v.

33. Hierover: C.A. Hage, Handhaving van privaatrecht door toezichthouders (diss. Leiden), Deventer: Wolters Kluwer 2017 (hierna: Hage 2017b).

34. Vierde nota van wijziging Wft, Kamerstukken II 2005/06, 29708, 19 , p. 317.

35. Hage 2017b, p. 14 e.v.

36. O.O. Cherednychenko, Toezichtcontractenrecht: vooruitgang in het burgerlijk recht?, Contracteren 2011, p. 12.

37. Hage 2017b, p. 284-285.
Dient de civiele rechter nu, in een dergelijk concreet geval waarin schade is opgetreden, ambtshalve vast te stellen dat de financiële onderneming een regel van gedragstoezicht heeft geschonden? Zo ja, is de rechter hierbij dan gebonden aan de grenzen van de rechtsstrijd?

In veel publiekrechtelijke toezichtnormen is de privaatrechtelijke invloed duidelijk herkenbaar. Ik wijs bijvoorbeeld op de in afdeling 4.2.3 Wft neergelegde plicht tot zorguuldige dienstverlening, de plicht tot voorkoming van overkreditering van art. 4:34 Wft, de algemene zorgplicht van art. 4:90 Wft en de best execution-verplichting van art. 4:90a Wft, alsmede daarop gebaseerde afgeleide regelgeving in het Besluit gedragstoezicht financiële ondernemingen (Bgfo) en de Nadere regeling gedragstoezicht financiële ondernemingen (Ngfo). Al deze plichten zijn onmiskenbaar bedoeld om zich in een zwakkere positie bevindende cliënten aanvullende bescherming te verlenen en de inherente ongelijkheid tussen de financiële ondernemer en de cliënt te compenseren. Doelstellingen waarvan de overeenkomst met consumentenbeschermende EUrichtlijnen zich aanstonds aandient. Daardoor kan de gedachte snel postvatten dat ook deze normen zich lenen voor ambtshalve toepassing.

Maar er is, zo werd ook in paragraaf 3 al naar voren gebracht, een groot verschil met de gevallen die ressorteren onder de consumentenbeschermende EU-richtlijnen. Waar die richtlijnen zien op privaatrechtelijke verhoudingen tussen consumenten en professionele partijen en vaak ook een duidelijke sanctie voorschrijven voor het geval de professionele partij een consumentenbeschermende bepaling schendt, beogen de uit financiële toezichtrichtlijnen voortvloeiende bepalingen iets geheel anders. $\mathrm{Zij}$ schrijven normen voor die in de verhouding tussen de financiële onderneming en de toezichthouder die is belast met het gedragstoezicht, de AFM, een rol spelen. Dat zij hun invloed ook in privaatrechtelijke verhoudingen doen gevoelen, maakt niet dat zij zonder meer op één lijn kunnen worden gesteld met de consumentenbeschermende EU-richtlijnen ten aanzien waarvan het $\mathrm{HvJ} \mathrm{EU}$ heeft geoordeeld dat voor de rechter een plicht bestaat tot ambtshalve toepassing van daaruit voortvloeiende omzettingswetgeving. In geval van consumentenbeschermende EU-richtlijnen is de ambtshalve toepassing een noodzakelijke voorwaarde voor een effectieve bescherming van de consument. Met betrekking tot financiële toezichtrichtlijnen garandeert het door de toezichthouder uitgeoefende toezicht een effectieve bescherming van marktpartijen, waaronder de consument.

Het HvJ EU lijkt dat ook te overwegen in de hiervoor besproken arresten in de zaken Genil en Nationale Nederlanden/ Van Leeuwen. De waarde van de publiekrechtelijke toezichtnormen in privaatrechtelijke verhoudingen is iets waar het $\mathrm{HvJ}$ EU zich slechts heel marginaal mee wenst in te laten. Als dat al gebeurt ter bescherming van een der partijen, lijkt dat vooral ter bescherming van de (professionele) financiële onderneming, en niet zozeer ter bescherming van de cliënt. 


\section{Maandblad \\ Vermogensrecht}

Immers, aanvullende privaatrechtelijke verplichtingen worden onderworpen aan functionaliteit/noodzakelijkheid en rechtszekerheid, opdat een financiële onderneming niet wordt geconfronteerd met verplichtingen waarvan zij het bestaan onmogelijk had kunnen bevroeden.

\section{Welke waarde in civilibus?}

Heeft het bestaan van een publiekrechtelijke toezichtbepaling in een privaatrechtelijk geschil dan in het geheel geen waarde. Nee, dat zou ik niet willen bepleiten. ${ }^{38}$ De vaststelling dat een financiële onderneming op haar van toepassing zijnde publiekrechtelijke toezichtbepalingen heeft geschonden, kan, zeker als deze bepalingen strekken ter bescherming van een consument, zeker haar invloed doen gevoelen in een privaatrechtelijk geschil tussen deze partijen. Alleen de doorwerking van deze vaststelling voltrekt zich via privaatrechtelijke (open) normen. En voor wat betreft de vraag naar de verplichting tot ambtshalve toepassing zijn die normen bepalend. Dat betekent dat als de rechter niet verplicht is om ambtshalve - buiten de grenzen van de rechtsstrijd - toepassing te geven aan een dergelijke privaatrechtelijke norm, hij dat mijns inziens ook niet wordt omdat de norm ingekleurd zou kunnen worden door publiekrechtelijke toezichtwetgeving.

De gedachte dat dat onrechtvaardig zou kunnen zijn voor de consument in kwestie, zou ik willen nuanceren. Ten eerste was, is en zal vermoedelijk ook in de toekomst blijken te zijn, de ratio voor een verplichting tot ambtshalve toepassing van consumentenbeschermende bepalingen dat de consument alleen op die wijze effectief kan worden beschermd. Als die bescherming ook op andere wijze kan worden gegarandeerd, verzet het EU-recht zich mijns inziens niet principieel tegen het uitblijven van ambtshalve ingrijpen. ${ }^{39}$ Ten tweede kan de rechter al heel veel bereiken door aanwending van zijn (instructie)bevoegdheden, zonder onmiddellijk tot ambtshalve ingrijpen buiten de grenzen van de rechtsstrijd over te gaan. $^{40}$

Het voorgaande neemt niet weg dat er ook argumenten kunnen worden aangevoerd voor het aanvaarden van een verplichting tot ambtshalve toetsing in geschillen waarin er een evidente ongelijkheid tussen partijen bestaat. Het compenseren van die ongelijkheid via een actievere houding van de civiele rechter heeft in Frankrijk wel ingang gevonden, waar ter ondersteuning van die plicht wordt gewezen op het in art. 6 van het Europees Verdrag tot bescherming van de rechten van de mens en de fundamentele vrijheden (EVRM) gecodificeerde equality of arms-beginsel. In Frankrijk heeft dat er echter toe geleid dat in de Code de la consommation een bepaling is opgenomen waarin de rechter wordt verplicht om ambtshalve toepassing te geven aan regels uit die Code. En dat lijkt mij

38. Zie recent nog van mijn hand over deze kwestie: A.G.F. Ancery, Het swappen van mededelingsplichten, MvV 2017, afl. 11, p. 332 e.v.

39. Ik merkte dat reeds op in mijn noot onder het Hueros-arrest in TvC 2014/3.

40. Hierover: Ancery 2012, p. 185 e.v. (hoofdstuk 9). ook de juiste route. Als de tendens zou zijn dat de civiele rechter steeds toepassing dient te geven aan bepalingen die een zwakkere partij beschermen, zelfs buiten de grenzen van de rechtsstrijd, is de wetgever aan zet om dat aan te geven. Het verder extrapoleren van de rechtspraak van het HvJ EU op dit punt zou er alleen maar toe leiden dat nog meer onduidelijkheden ontstaan over de wijze waarop daar dan weer uitvoering aan dient te worden gegeven. ${ }^{41}$
41. Vgl. voor vragen die leven met betrekking tot de verplichting tot ambtshalve toepassing van consumentenrecht het LOVCK-rapport 'Ambtshalve toetsing II', te raadplegen via: www.rechtspraak.nl/ SiteCollectionDocuments/Rapport-ambtshalve-toetsing-II-versienovember-2014.pdf. En over de moeilijkheid om te bepalen tot hoever EU-rechtelijke verplichtingen precies reiken: R. Westrik, Verborgen privaatrecht. Hoe het geldende recht te kennen?, Zutphen: Paris 2016, m.n. p. 100 e.v. 